\title{
Working Memory and Response Inhibition as One Integral Phenotype of Adult ADHD? A Behavioral and Imaging Correlational Investigation
}

Journal of Attention Disorders

I7(6) 470-482

(C) 2012 SAGE Publications

Reprints and permissions:

sagepub.com/journalsPermissions.nav

DOI: | 0.1 | 77// 0870547| | 429702

jad.sagepub.com

(S)AGE

\author{
Martin Schecklmann 1,2, Ann-Christine Ehlis ${ }^{2,4}$, Michael M. Plichta ${ }^{2,3}$, \\ Thomas Dresler ${ }^{2}$, Monika Heine ${ }^{2}$, Andrea Boreatti-Hümmer ${ }^{2}$, \\ Marcel Romanos ${ }^{2,5}$, Christian Jacob ${ }^{2}$, Paul Pauli ${ }^{2}$, and Andreas J. Fallgatter ${ }^{2,4}$
}

\begin{abstract}
Objective: It is an open question whether working memory (WM) and response inhibition (RI) constitute one integral phenotype in attention deficit hyperactivity disorder (ADHD). Method: The authors investigated 45 adult ADHD patients and $4 \mathrm{I}$ controls comparable for age, gender, intelligence, and education during a letter n-back and a stop-signal task, and measured prefrontal oxygenation by means of functional near-infrared spectroscopy. Results: The authors replicated behavioral and cortical activation deficits in patients compared with controls for both tasks and also for performance in both control conditions. In the patient group, 2-back performance was correlated with stop-signal reaction time. This correlation did not seem to be specific for WM and RI as I-back performance was correlated with go reaction time. No significant correlations of prefrontal oxygenation between WM and RI were found. Conclusion: The authors' findings do not support the hypothesis of WM and RI representing one integral phenotype of ADHD mediated by the prefrontal cortex. (J. of Att. Dis. 2013; 17(6) 470-482)
\end{abstract}

\section{Keywords}

ADHD, n-back, stop signal, near-infrared spectroscopy, impulsivity

\section{Introduction}

Patients with ADHD show clinical symptoms of hyperactivity, impulsivity, and attention problems and are subsumed in the hyperactive-impulsive, inattentive, or combined subtype according to the Diagnostic and Statistical Manual of Mental Disorders (4th ed.; DSM-IV; American Psychiatric Association, 1994; Sass, Wittchen, \& Zaudig, 1996). In addition, problems in executive functions such as working memory (WM) and response inhibition (RI) are considered etiologically relevant markers of the disorder (Castellanos \& Tannock, 2002), leading to the hypothesis of disturbed prefrontal functioning in ADHD (Durston, 2003; Schneider, Retz, Coogan, Thome, \& Rosler, 2006). Deficits in these executive functions have been suggested as endophenotypes (i.e., intermediate phenotypes) linking neurobiology and clinical phenotype (Gottesman \& Gould, 2003; Zobel \& Maier, 2004). Barkley (1997) and Sonuga-Barke (2002, 2005) suggested that deficits in WM and RI are part of one common psychopathological pathway that may present on a phenotypic level as increased impulsivity. Barkley postulated disturbed inhibition as core deficit in ADHD resulting in dysfunctional WM processes. However, the question whether both processes are one integral or two distinct phenotypes in ADHD remains unresolved.

There is a body of evidence from behavioral and imaging meta-analyses indicating that WM and RI or frontal executive processes in general are disturbed in ADHD (Boonstra, Oosterlaan, Sergeant, \& Buitelaar, 2005; Dickstein, Bannon, Castellanos, \& Milham, 2006; Hervey, Epstein, \& Curry, 2004; Lijffijt, Kenemans, Verbaten, \& van Engeland, 2005; Martinussen, Hayden, Hogg Johnson, \& Tannock, 2005; Schneider et al., 2006; Schoechlin \& Engel, 2005; Willcutt,

\footnotetext{
'University Regensburg, Germany

${ }^{2}$ University of Würzburg, Germany

${ }^{3}$ University of Heidelberg, Mannheim, Germany

${ }^{4}$ University of Tübingen, Germany

${ }^{5}$ University Hospital of München, Germany

Corresponding Author:

Martin Schecklmann, Department of Psychiatry and Psychotherapy, University Regensburg, Universitätsstraße 84, 93053 Regensburg, Germany.

Email: martin.schecklmann@medbo.de
} 
Doyle, Nigg, Faraone, \& Pennington, 2005; Woods, Lovejoy, $\&$ Ball, 2002). These findings are primarily based on group differences between patients and controls, that is, patients differ from controls in mean reaction times, error rate, and brain activity in certain regions. However, comparing group means cannot reveal information about a possible association of the two functions. An association between two measures is given when participants with good performance/ high brain activity in one task also show an accompanying good performance/high brain activity in the other task. Vice versa, participants with low performance/low brain activity in one task should display similar results in the other task, too. Thus, correlational analyses are a useful strategy to reveal information regarding the integration of two functions in one phenotype.

To further contribute to the unresolved question whether RI and WM represent an integral executive phenotype, the aim of our study was-beside replication of the known group differences - to investigate the correlation between WM and RI operationalized by an n-back and a stop-signal task, respectively, in adult patients with ADHD and healthy controls. Furthermore, we correlated the dependent variables with trait impulsivity evaluated by a questionnaire, as inhibition tasks and trait impulsivity questionnaires represent different operationalizations of the clinical symptom of impulsivity (Chamberlain \& Sahakian, 2007; Winstanley, Eagle, \& Robbins, 2006). In addition to behavioral data, we investigated correlations of brain activation during the performance of both tasks. We concentrated on the prefrontal cortex as patients with ADHD show differences in these areas especially for WM and RI (Aron \& Poldrack, 2005; Schecklmann et al., 2010). We used functional near-infrared spectroscopy (fNIRS) representing an optical approach to measure cortical blood flow changes (Hoshi, 2007) and an innovative research tool that proved to be useful in investigating psychiatric disorders (Fallgatter, Ehlis, Wagener, Michel, \& Herrmann, 2004). Cortical blood flow changes as measured by fNIRS or functional magnetic resonance imaging (fMRI) serve as indicators of brain activity. Neuronal activity is associated with systematic blood flow changes (increase of oxygenated and decrease of deoxygenated hemoglobin), a phenomenon which is known as neurovascular coupling (Heeger \& Ress, 2002; Logothetis \& Wandell, 2004).

To date, 10 studies have been published that correlated WM and RI in ADHD patients or controls or both (Alderson, Rapport, Hudec, Sarver, \& Kofler, 2010; Clark et al., 2007; Geurts, Verte, Oosterlaan, Roeyers, \& Sergeant, 2005; Mahone et al., 2005; McNab et al., 2008; Mullane \& Corkum, 2007; Pasini, Paloscia, Alessandrelli, Porfirio, \& Curatolo, 2007; Sonuga-Barke, Dalen, Daley, \& Remington, 2002; Tsujimoto, Kuwajima, \& Sawaguchi, 2007; Verte, Geurts, Roeyers, Oosterlaan, \& Sergeant, 2006; Table 1). As we were interested in RI, we abstained from listing studies that used interference tasks. The reported correlation analyses were not in all cases the primary research question, used very different operationalizations of WM and RI, only two studies investigated adult participants (one of them patients), and no unequivocal support for a high correlation of WM and RI could be found. The effect sizes (= magnitudes) of the correlation coefficients ranged from .01 to .62 . Only one study additionally investigated brain activation using fMRI (McNab et al., 2008). However, the authors did not correlate brain activity between these tasks; instead, they simply identified brain regions that were commonly active during both tasks for the whole group.

Under the premise that WM and RI are associated processes, we would expect correlations with at least high correlation coefficients ( $r>.5$; explained variance $25 \%$ ) between WM and RI tasks for performance and prefrontal activity.

\section{Method}

\section{General Procedures}

After diagnosis by two physicians (M.H., A.B.-H., or C.J.) according to DSM criteria, the responsible examiner (M.S.) contacted the participants and obtained informed consent. Diagnosis information included $D S M-I V$ criteria for ADHD, impulsivity (I7; Eysenck \& Eysenck, 1977), and the Wender Utah Rating Scale-Short Version (WURS-k; RetzJunginger et al., 2003). Before the fNIRS measurement, data on intelligence, handedness, present drug, and medication consumption were collected on-site via questionnaires and interview. After explanation and practice of the tasks, the probe set was placed on the head and the measurements were started. The order of the WM and RI tasks was counterbalanced. The instructions and measurements were done by the main investigator (M.S.) or a technical assistant.

All used measures have shown to be highly reliable, that is, n-back task (Jaeggi, Buschkuehl, Perrig, \& Meier, 2010), stop-signal (Soreni, Crosbie, Ickowicz, \& Schachar, 2009), fNIRS (Plichta, Herrmann, et al., 2007; Schecklmann, Ehlis, Plichta, \& Fallgatter, 2008), and I7 (Eysenck \& Eysenck, 1980). Validity studies are less in number; however, promising results have been found. Beside the face validity of all tasks, the n-back task showed moderate correlations with other indices of WM (Jaeggi et al., 2010), and fNIRS was shown to be highly correlated with other imaging techniques (Huppert, Hoge, Diamond, Franceschini, \& Boas, 2006; Rovati, Salvatori, Bulf, \& Fonda, 2007). The stop-signal task and also I7 are considered as measures of impulsivity (Chamberlain \& Sahakian, 2007).

\section{Participants}

We examined 45 adult patients with ADHD (DSM-IV) and 41 controls. Participants were examined by experienced physicians using the structured clinical interview for $D S M-I V$ (SCID-I, SCID-II; Wittchen, Zaudig, \& Fydrich, 
Table I. Studies Correlating Working Memory and Response Inhibition Tasks in Chronological Order.

\begin{tabular}{|c|c|c|c|c|}
\hline & $\begin{array}{c}\text { Sample characteristics } \\
\text { (years) }\end{array}$ & Working memory task & $\begin{array}{c}\text { Response } \\
\text { inhibition task }\end{array}$ & Correlation coefficient $r$ \\
\hline $\begin{array}{l}\text { Geurts, Verte, } \\
\text { Oosterlaan, Roeyers, } \\
\text { and Sergeant (2005) }\end{array}$ & $\begin{array}{l}\text { Children }(6-13): 54 \\
\text { ADHD, } 4 \text { I autism, } \\
4 \mid \text { controls }\end{array}$ & Self-ordered pointing & $\begin{array}{l}\text { stop-signal } \\
\text { task, }{ }^{\text {a slowing }} \\
\text { of continuous } \\
\text { circle tracing, } \\
\text { opposite } \\
\text { pronouncing } \\
\text { (three tasks) }\end{array}$ & $\begin{array}{l}\text { ADHD: . } 18 \\
\text { Controls: } .19 \\
\text { Whole group: .01-.63 (.18) }\end{array}$ \\
\hline Mahone et al. (2005) & $\begin{array}{l}\text { Children }(3-6.5): 40 \\
\text { ADHD, } 40 \text { controls }\end{array}$ & Self-ordered pointing & $\begin{array}{l}\text { Auditory } \\
\text { continuous } \\
\text { performance }^{\mathrm{a}}\end{array}$ & Group not specified: .09 \\
\hline $\begin{array}{l}\text { Verte, Geurts, Roeyers, } \\
\text { Oosterlaan, and } \\
\text { Sergeant (2006) }\end{array}$ & $\begin{array}{l}\text { Children (6-13): } 65 \\
\text { ADHD, } 82 \text { controls }\end{array}$ & Self-ordered pointing & stop-signal task ${ }^{\mathrm{a}}$ & $\begin{array}{l}\text { ADHD: } .25 \\
\text { Controls: } .10\end{array}$ \\
\hline Clark et al. (2007) & $\begin{array}{l}\text { Adults }(28 \pm 9,25 \pm 5) \text { : } \\
20 \text { ADHD, } 16 \\
\text { controls }\end{array}$ & Self-ordered pointing & stop-signal task & $\begin{array}{l}\text { ADHD: } .538 \\
\text { Controls: }-.133\end{array}$ \\
\hline $\begin{array}{l}\text { Mullane and Corkum } \\
\text { (2007) }\end{array}$ & $\begin{array}{l}\text { Children (6.5-II.5): I5 } \\
\text { ADHD, I } 5 \text { controls }\end{array}$ & $\begin{array}{l}\text { Counting task and digit } \\
\text { span backward (two tasks } \\
\text { integrated) }\end{array}$ & stop-signal task ${ }^{\mathrm{a}}$ & $\begin{array}{l}\text { Whole group: } .37 \text { (.28 after } \\
\text { correction for age and } \\
\text { intelligence) }\end{array}$ \\
\hline $\begin{array}{l}\text { Pasini, Paloscia, } \\
\text { Alessandrelli, Porfirio, } \\
\text { and Curatolo (2007) }\end{array}$ & $\begin{array}{l}\text { Children (8-14): } 50 \\
\text { ADHD, } 44 \text { controls }\end{array}$ & $\begin{array}{l}\text { Visual-object, visual-spatial, and } \\
\text { phonological n-back (three } \\
\text { tasks) }\end{array}$ & $\begin{array}{l}\text { Visual } \\
\text { continuous } \\
\text { performance }^{c}\end{array}$ & $\begin{array}{l}\text { ADHD: associated (statistics } \\
\text { not reported) } \\
\text { Controls: not reported }\end{array}$ \\
\hline $\begin{array}{l}\text { Sonuga-Barke et al. } \\
(2002)\end{array}$ & $\begin{array}{l}160 \text { children }(3-5.5): \\
30 \% \text { with ADHD- } \\
\text { type problems }\end{array}$ & Auditory sequencing & $\begin{array}{l}\text { "Puppet } \\
\text { theater" go/ } \\
\text { no-go }\end{array}$ & $\begin{array}{l}\text { Whole group: } .57 \text { (.12 after } \\
\text { correction for age and } \\
\text { intelligence) }\end{array}$ \\
\hline $\begin{array}{l}\text { Tsujimoto, Kuwajima, and } \\
\text { Sawaguchi (2007) }\end{array}$ & $\begin{array}{l}\text { Two children control } \\
\text { samples ( } 5-6 \text { and } \\
8-9)\end{array}$ & $\begin{array}{l}\text { Visual-spatial and auditory } \\
\text { n-back (two tasks) }\end{array}$ & Visual go/no-go & $\begin{array}{l}\text { Younger group: } .38 \text { and } .40 \\
\text { Older group:. } 17 \text { and } .01\end{array}$ \\
\hline McNab et al. (2008) & $\begin{array}{l}\text { I I adult controls } \\
(22-34)\end{array}$ & $\begin{array}{l}\text { Visual-verbal and visual-spatial } \\
\text { match-to-sample (two tasks) }\end{array}$ & $\begin{array}{l}\text { stop-signal task }{ }^{\mathrm{a}} \\
\text { and visual go/ } \\
\text { no-go (two } \\
\text { tasks) }\end{array}$ & $.15-.62$ \\
\hline $\begin{array}{l}\text { Alderson, Rapport, } \\
\text { Hudec, Sarver, and } \\
\text { Kofler }(2010)\end{array}$ & $\begin{array}{l}\text { Children }(8-12) \text { : } 14 \\
\text { ADHD, I } 3 \text { controls }\end{array}$ & $\begin{array}{l}\text { Visual-spatial block sequence } \\
\text { ordering (tapping) and } \\
\text { letter-number sequencing } \\
\text { (pronouncing; two tasks) }\end{array}$ & stop-signal task ${ }^{\mathrm{a}}$ & Whole group: .28-.57 \\
\hline
\end{tabular}

${ }^{a}$ Visual presented stimuli with acoustic stop signal.

b Including additional executive functions beside working memory and response inhibition.

'With commission errors as dependent variable that indicates a measure for response inhibition.

1997) and an open anamnestic interview to evaluate psychiatric, neurological, and somatic conditions. Participants were recruited and diagnosed in the framework of a nationally funded research project (Deutsche Forschungsgemeinschaft, KFO 125-1; Jacob \& Lesch, 2006) ensuring a qualitatively high diagnostic procedure, that is, diagnosis by two physicians experienced with ADHD including the assessment of the DSM-IV diagnostic criteria, additional supportive information by reports of related persons, and reports of retrospective symptoms if available. The patient sample consisted of 33 patients with combined, 9 with inattentive, and 3 with hyperactiveimpulsive subtype. Participants with serious somatic and neurological diseases and controls with any history of psychiatric disease were excluded from the analysis. Three patients took antidepressant medication, and 6 patients were treated with methylphenidate (MPH) that was discontinued at least 1 day prior to the measurement (equaling more than five half-life periods of MPH; Pliszka, 2007). In all, 11 patients had a psychiatric comorbidity (depression, $n=9$; eating disorder, $n=1$; cocaine misuse, $n=1$ ), and 33 patients were diagnosed with one or more personality disorders according to SCID-II. Somatic comorbidities were dysfunctions of the thyroid (4 patients and 5 controls), cardiovascular system ( 2 patients and 3 controls), or asthma (2 controls), all of which were treated with corresponding medication. Separate analyses eliminating patients with constant MPH medication, Axis 
Table 2. Sample Characteristics (mean \pm standard deviation).

\begin{tabular}{|c|c|c|c|}
\hline & Controls & Patients & Statistical parameters \\
\hline Age (years) & $36.1 \pm 10.1(n=4 I)$ & $36.4 \pm 9.9(n=45)$ & $T=0.149 ; d f=84 ; p=.882$ \\
\hline Intelligence (IQ) & $118.5 \pm 13.2(n=41)$ & $118.0 \pm 15.2(n=43)$ & $T=0.172 ; d f=82 ; p=.864$ \\
\hline Graduation (no A-levels/A-levels) & $18 / 23$ & $21 / 24$ & $\chi^{2}=0.066 ; d f=1 ; p=.797$ \\
\hline Head perimeter $(\mathrm{cm})$ & $57.0 \pm 2.3(n=38)$ & $57.3 \pm 2.5(n=42)$ & $T=0.601 ; d f=78 ; p=.550$ \\
\hline Gender (female/male) & $21 / 20$ & $21 / 24$ & $\chi^{2}=0.178 ; d f=1 ; p=.673$ \\
\hline Handedness (right/left/ambidext) & $37 / 2 / 2$ & $38 / 4 / 3$ & $\chi^{2}=0.695 ; d f=2 ; p=.706$ \\
\hline Nicotine use (nonsmoker/smoker) & $35 / 6$ & $26 / 19$ & $\chi^{2}=7.919 ; d f=1 ; p=.005$ \\
\hline Trait impulsivity (I7) & $5.5 \pm 3.2(n=4 I)$ & $10.3 \pm 4.1(n=42)$ & $T=5.976 ; d f=8 \mathrm{I} ; p<.00 \mathrm{I}$ \\
\hline $\begin{array}{l}\text { Childhood ADHD symptoms } \\
\text { (WURS-k) }\end{array}$ & $\mid 3.6 \pm 8.5(n=4 \mid)$ & $33.4 \pm 11.8(n=45)$ & $T=8.8 I 5 ; d f=84 ; p<.00 I$ \\
\hline
\end{tabular}

Note: WURS-k = Wender Utah Rating Scale-Short Version.

I psychiatric comorbidity, or medication intake revealed no differences in results. Groups were comparable for age, intelligence (according to the Mehrfachwahl-WortschatzIntelligenztest MWT-B; Lehrl, 2005), educational achievement, head perimeter, gender, and handedness (Table 2). To assure that the same brain regions have been covered in patients and controls, we checked if head perimeter was the same in both groups. The group of patients had a higher prevalence of smokers, and higher ADHD-specific scores in the I7 impulsivity (Eysenck, Daum, Schugens, \& Diehl, 1990) and in the short version of the WURS-k (RetzJunginger et al., 2003; Table 2). We had a high elimination rate (original sample: 105 patients and 55 controls) due to strict exclusion criteria as specified in the next sentences. A total of 20 patients and 9 controls were excluded due to an insufficient task comprehension ( $>20 \%$ errors in the 1-back task or a rigid response style in the stop-signal task that caused the threshold algorithm to fail; see below). Six patients and 2 controls showed fNIRS artifacts detected by visually prominent outliers in mean oxygenation of regions of interest (ROIs). In all, 34 patients and 3 controls did not complete both tasks for several reasons (discomfort due to pressure caused by the probe set, discontinuation of the measurement if the 45-min procedure was experienced as too strenuous, technical problems). Patients included in the analysis showed nonsignificant higher scores in impulsivity in contrast to eliminated patients as measured with $\mathrm{I} 7$ $(T=0.324, p=.747)$ and $D S M$ impulsivity $(T=1.809$, $p=.073$ ). The study was approved by the Ethics Committee of the University of Würzburg. All procedures involved were in accordance with the fifth revision of the Declaration of Helsinki. All participants gave written informed consent after comprehensive explanation of the procedures.

\section{WM and RI Tasks}

Participants were seated at 1-m distance to a computer screen and were instructed to sit relaxed and to avoid any major body movement. Responses were given via a standard computer keyboard. WM was operationalized by a letter n-back task comprising a 2-back and a 1-back condition presented in blocks of 30-s duration. Every condition was repeated 3 times, starting with the 2-back condition followed by the 1-back condition (order: 2-1-2-1-2-1). Between task phases, rest phases of 30-s duration were presented including instructions for the next block on the screen. For the 2-back condition (high WM load), participants were instructed to press the space bar with their right hand whenever the letter was identical to the letter presented two trials before. For the 1-back condition (low WM load, control condition), a response had to be given when two identical letters were presented consecutively. Stimulus material consisted of white letters on black background (A, B, C, D, E, F, G, H, J, and L) presented for $300 \mathrm{~ms}$ followed by a blank screen for $1,700 \mathrm{~ms}$. Each block contained 15 trials with 4 target letters in pseudorandomized order resulting in 45 trials and 12 target letters for each condition. The n-back task lasted about 6 min. As dependent variable, we used a measure of efficiency (Kirk, Mazzocco, \& Kover, 2005) to overcome possible speed accuracy trade-offs. High scores of this efficiency measure indicate high efficiency.

RI was operationalized by a stop-signal task containing short and long go-trials (control condition) and stop trials (RI condition). One trial consisted of a white fixation cross $(500 \mathrm{~ms})$, then a black screen $(500 \mathrm{~ms})$, followed by the white letters A or B $(500 \mathrm{~ms})$ and closing by a jittered black screen (short go-trials: 1,000-2,000 ms; long go-trials and stop trials: 5,000-6,000 ms). The order of trials was randomized for each participant. The paradigm contained 100 short go-trials, 50 long go-trials, and 50 stop trials $(25 \%$ of all stimuli). Although the mixed use of short and long trials is not common in stop-signal literature, we used short go-trials to shorten the complete stop-signal task time (about $15 \mathrm{~min}$ ). Only long trials were used for analyses as only the long go and the (long) stop trials were comparable. Participants included in our analyses were not irritated or bored due to 
the long trials and completed the task in a correct manner (40\%-60\% successful stop-signal trials as necessary for an effective threshold algorithm; see below). During go-trials, participants had to press the left arrow key with their right index finger seeing an " $A$ " and the right arrow key with their right ring finger seeing a "B." For stop trials, the white letter A or B turned red after a certain time, that is, a certain stimulus onset asynchrony (SOA). For these trials, participants had to stop their initiated responses. For the first stop trial, a SOA of $200 \mathrm{~ms}$ was set. For the following stop trials, the SOA was elongated or shortened by $25 \mathrm{~ms}$ depending on the reaction to the previous stop trial (i.e., whether the response was successfully stopped or not). Shortening and elongation of SOA based on the last stop trial response should result in a total of $50 \%$ successful and $50 \%$ unsuccessful stop trials over the course of the experiment (threshold algorithm). In accordance with the "race model of stop-signal tasks" (Band, van der Molen, \& Logan, 2003; Logan, 1994; Logan, Schachar, \& Tannock, 1997) for stop trials, it is assumed that the go process of the go stimulus (variable reaction times over trials) competes with the stop process of the stop stimulus (constant length) resulting in a button response or not. Shortening of SOA made the subsequent stop trials easier, and elongating made it more difficult. For the 50\% threshold, the stop process has the same probability to win as the go process, and the stop-signal reaction time (SSRT) can be calculated as the difference of the mean reaction time for go stimuli and the mean SOA. As dependent variables, we used mean reaction time during long go-trials and SSRT. The order of the WM and RI tasks was counterbalanced across participants.

\section{Measurement and Analysis of fNIRS Signals}

For the fNIRS measurement, we used a continuous wave multichannel system (ETG-4000 Optical Topography System; Hitachi Medical Co., Japan) using two different wavelengths ( $695 \pm 20$ and $830 \pm 20 \mathrm{~nm})$ and a time resolution of $10 \mathrm{~Hz}$ to measure relative changes of absorbed near-infrared light. These changes are transformed into concentration changes of $\mathrm{O}_{2} \mathrm{Hb}$ (oxygenated hemoglobin) and $\mathrm{HHb}$ (deoxygenated hemoglobin) as indicators for brain activity by means of a modified Beer-Lambert law (Obrig \& Villringer, 2003). The unit is $\mathrm{mmol} \times \mathrm{mm}$, that is, changes of chromophore concentration depend on the path length of the near-infrared light. We used one probe set (plastic panel) of optodes consisting of 17 light emitters and 16 detectors with an interoptode distance of $3 \mathrm{~cm}$. A measuring point of activation (channel) was defined as the region between one emitter and one detector resulting in 52 channels covering an area of $30 \times 6 \mathrm{~cm}^{2}$ on the scalp. The panel was fastened to the head by elastic straps. The panel was placed on the head with regard to the relevant standard positions of the international 10-20 system for electroencephalogram electrode placement (Jasper, 1958; Okamoto et al., 2004). The middle inferior optode was placed over Fpz (frontopolar central electrode position) on the forehead, and the inferior row of optodes was oriented toward T3 and T4 (temporal electrode positions), respectively (see Figure 1). The electrode positions can be mapped to brain areas (Okamoto et al., 2004).

Before statistical analysis of functional data, the high frequency portion of the signal was removed by calculating a moving average with a time window of $5 \mathrm{~s}$. Low frequencies were filtered by a high-pass filter with nine discrete cosine basis functions. We used the general linear model according to fMRI and fNIRS literature (Friston et al., 1995; Plichta, Heinzel, Ehlis, Pauli, \& Fallgatter, 2007; Plichta, Herrmann, et al., 2007), with a gamma function serving as the model for the hemodynamic response function (HRF). For $\mathrm{O}_{2} \mathrm{Hb}$ we used a peak time of $7.5 \mathrm{~s}$ and for $\mathrm{HHb} 8.5 \mathrm{~s}$. The beginning of each stimulus was modeled as a delta stick function and folded with the HRF resulting in two predictor variables for WM (2- and 1-back) and in five predictors for RI (short and long go-trials, successful and unsuccessful stop trials, and errors independent of the condition). For statistical analyses, we only used long go-trials and successful stop trials. Failed stop trials would include error monitoring processes in addition to the stop process, so analysis of these trials would be ambiguous. Betas were estimated by the method of least squares indicating the amplitude of the HRF.

Then, we defined specific ROIs for which the mean of the betas was calculated; ROIs were defined by the 13 channels ( $25 \%$ of 52 channels) with the highest significant oxygenation (Plichta, Herrmann, et al., 2007; Tegeler, Strother, Anderson, \& Kim, 1999) mirrored by $\mathrm{O}_{2} \mathrm{Hb}$ increases and $\mathrm{HHb}$ decreases. ROIs were separately calculated for $\mathrm{O}_{2} \mathrm{Hb}$ and $\mathrm{HHb}$, and separately for each group. When patients with ADHD and controls showed differences in the channels with the highest oxygenation, significant channels of both groups constituted the ROI. This could be done as significant channels that differed between groups always showed the same oxygenation pattern and were localized adjacently (1 channel apart). Single significant channels spatially separated from the main cluster of significant channels ( 2 and more channels away) were excluded. For both chromophores, we defined particular ROIs as $\mathrm{O}_{2} \mathrm{Hb}$ and $\mathrm{HHb}$ often show different spatial specificity (Plichta, Herrmann, et al., 2007). For the control conditions (1-back and go-trials), and for the WM and RI conditions (2-back and successful stop trials), we defined the ROIs by $t$ tests against zero. All procedures for the definition of the ROIs were chosen in a data-driven way to overcome the possibility of small correlation coefficients due to a suboptimal estimation of brain oxygenation. For statistical analyses, we used analyses of variance (ANOVAs), two-sided student $t$ tests, $\chi^{2}$ test for independence, and Pearson's correlation 


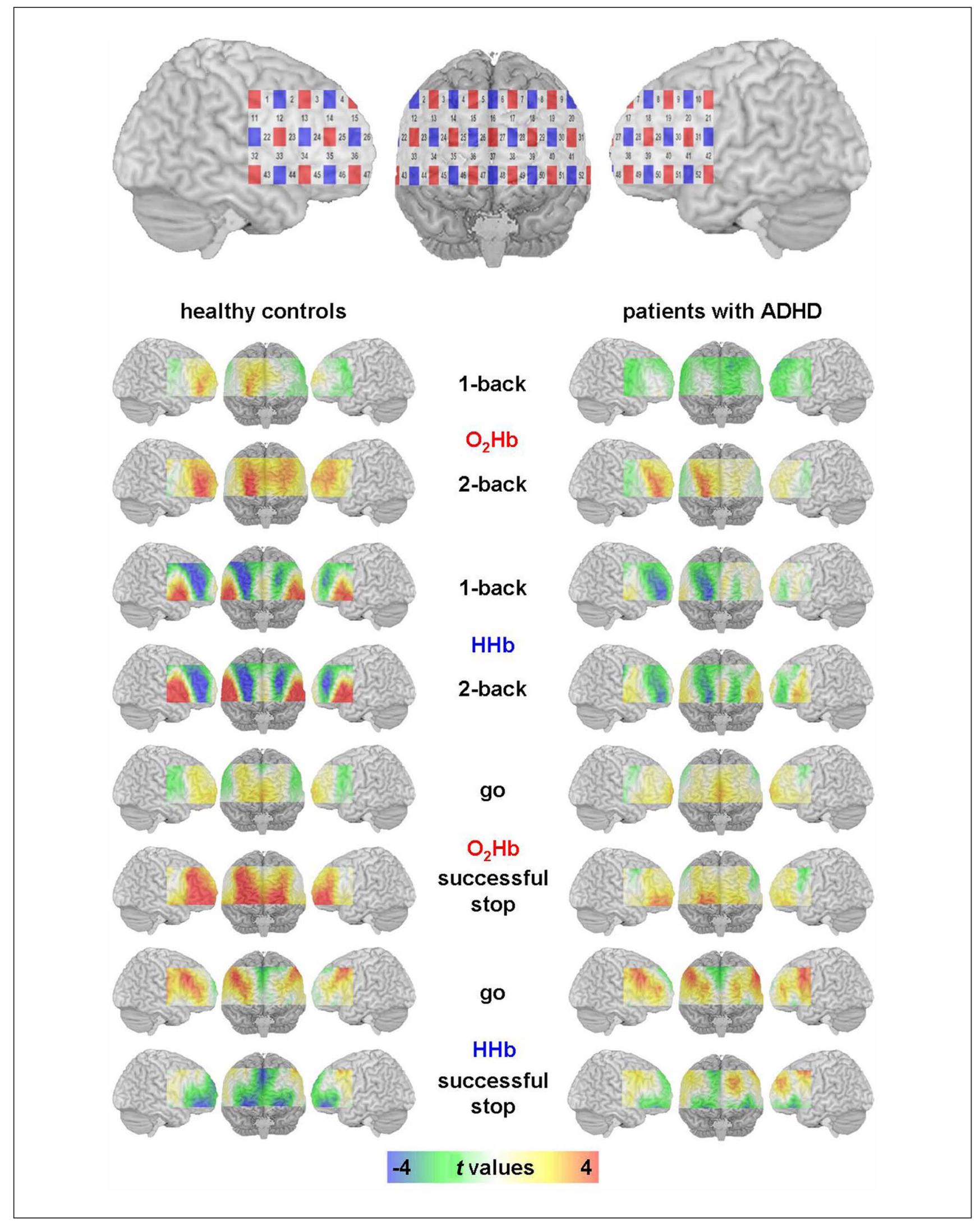

Figure I. Probe set arrangement and brain activation. Top: Arrangement of optodes (red = emitters; blue $=$ detectors) and channels (numbers) over an exemplary brain. Bottom: T-maps of brain activation as elicited by $t$ tests against zero. 
coefficients. For imaging data, we used the ROIs for analyses.

\section{Results}

\section{Behavioral Data}

We calculated repeated-measures ANOVAs $(d f 1=1$; $d f 2=84$ ) with the repeated-measures factor "task condition" (1-back and 2-back; go and stop) and the betweenparticipant factor "group" (ADHD and controls). We found significant main effects of condition (n-back: $F=187.6$, $p<.001$; stop task: $F=702.2, p<.001$ ), that is, 2-back had lower efficiency scores than 1-back, and SSRT was shorter than go reaction time (RT; Figures 2). The 2-back condition was more difficult than the 1-back condition. It is expected that the SSRT is shorter than the go RT as the SSRT is a difference value of the go RT and the mean SOA (see "Method" section). We also found main effects of group (n-back: $F=17.9, p<.001$; stop-signal: $F=8.8, p=.004$ ), that is, patients had lower efficiency and longer reaction times. The interaction effects were not significant (n-back: $F<$ $0.1, p=.972$; stop-signal: $F<0.1, p=.844$ ), that is, patients had lower efficiency scores and longer reaction times independent of the task condition. Thus, patients showed lower 2-back efficiency and elongated SSRT (reduced inhibition), but also lower 1-back efficiency and elongated go RT, that is, they did not show specific WM or RI deficits. Specific WM or RI group effects would have been indicated by significant interaction effects, that is, more prominent deficits of the patients during 2-back and stop-signal in contrast to the control conditions.

Correlation analyses for the controls showed no significant correlations with low effect sizes (Figure 2). Neither the control conditions (1-back efficiency with go RT; $r=$ $-.125, p=.435$ ) nor the actual tasks (2-back efficiency with SSRT; $r=-.113, p=.483$ ) were significantly correlated. For the patients, control conditions $(r=-.411, p=.005)$ and actual tasks $(r=-.358, p=.016)$ were negatively correlated, that is, the higher 1-back efficiency the lower go RT, and the higher 2-back efficiency the lower SSRT. Both significant correlations indicated a medium effect size according to Cohen (Cohen, 1988). Thus, negative correlations represent positive associations, that is, the higher n-back efficiency the faster reaction time.

Correlations with trait impulsivity revealed marginally significant correlations (small effect sizes) of n-back efficiency and no correlations of go RT and SSRT with $\mathrm{I} 7$ impulsivity (1-back: $r=-.277, p=.079$; 2-back: $r=-.280, p=.076$; go: $r=-.019, p=.908$; stop: $r=.094, p=.560)$ in the control group (Figure 2). In the patient group, negative correlations of impulsivity with go RT ( $r=-.355, n=42, p=.021)$ and SSRT $(r=-.477, p=.001)$ were found, whereas positive correlations of impulsivity with 1-back $(r=.398, p=.009)$ and 2-back ( $r=.443, p=.009)$ efficiency emerged (medium effect sizes). The significant correlations indicate positive associations of trait impulsivity and performance, that is, the more impulsive the higher efficiency during n-back conditions, and the more impulsive the shorter go RT (faster) and SSRT (superior inhibition).

To get more definite information of the association of impulsivity with performance in the patient group, we calculated correlations between DSM-IV impulsivity scores and performance measures and found no significant correlations (1-back: $r=.249, p=.103$; 2-back: $r=.109, p=.482$; go: $r=.038, p=.805$; stop: $r=.138, p=.372)$. $D S M-I V$ impulsivity scores and I7 impulsivity also did not correlate $(r=.257, p=.101)$.

\section{fNIRS Data}

Basal fNIRS activations for the respective conditions indicated by t-maps are depicted in Figure 1. For both groups, during 1-back and 2-back, highest $t$ values (positive for $\mathrm{O}_{2} \mathrm{Hb}$ and negative for $\mathrm{HHb}$, indicating brain activation) were found over the lateral medial parts of the probe set representing brain activity over the dorso-lateral prefrontal cortex (DLPFC; Figures 1 and 2). Channels with the highest oxygenation constituted the ROIs (top 25\% significant active channels for the $t$ tests; compare "Method," compare Figure 1) for 1-back $\left(\mathrm{O}_{2} \mathrm{Hb}: 15,25,26,35,46\right.$; $\mathrm{HHb}: 1,2$, $3,13,14,18,24,25,28,35,36,46)$ and 2-back $\left(\mathrm{O}_{2} \mathrm{Hb}: 13\right.$, 14, 18, 19, 24, 25, 26, 28, 29, 35, 36, 39, 46; HHb: 2, 3, 13, $14,18,24,25,28,29,35,36,39,46,49)$. Repeatedmeasures ANOVAs according to the behavioral level analyses were calculated for the ROIs. For $\mathrm{O}_{2} \mathrm{Hb}$ we found a significant main effect of condition $(F=10.9, p=.001)$ and a group effect with a statistical trend $(F=3.9, p=.051)$. The interaction effect was not significant $(F<0.1, p=.818)$. Thus, 2-back showed higher $\mathrm{O}_{2} \mathrm{Hb}$ concentration changes in contrast to 1-back in the DLPFC, and ADHD patients had lower $\mathrm{O}_{2} \mathrm{Hb}$ changes than controls independent of the n-back condition. For $\mathrm{HHb}$, we found no significant effects (condition: $F=2.3, p=.135$; group: $F=0.3, p=.613$; interaction: $F<0.1, p=.880$ ).

For both groups and both chromophores, go-trials were associated with oxygenation over frontopolar regions (O Hb ROI: 26, 27, 35, 36, 37, 38, 46, 47; HHb ROI: 5, 6, $16)^{2}$; successful stop trials were accompanied with oxygenation in inferior frontal cortical areas ( $\mathrm{O}_{2} \mathrm{Hb}$ ROI: $3,13,14$, $24,35,36,38,39,45,46,47,48,49,50$; HHb ROI: 5, 16, $26,35,36,39,40,45,46,47,49,50,51)$. For $\mathrm{O}_{2} \mathrm{Hb}$, ANOVAs indicated a significant condition and interaction effect (condition: $F=9.2, p=.003$; group: $F=2.7, p=.108$; interaction: $F=6.9, p=.010$ ). Post hoc $t$ tests indicate that brain activity was higher during successful stops in contrast to the go condition only in the group of controls (ADHD: $T=0.3, d f=44, p=.776$; controls: $T=3.9, d f=40$, 

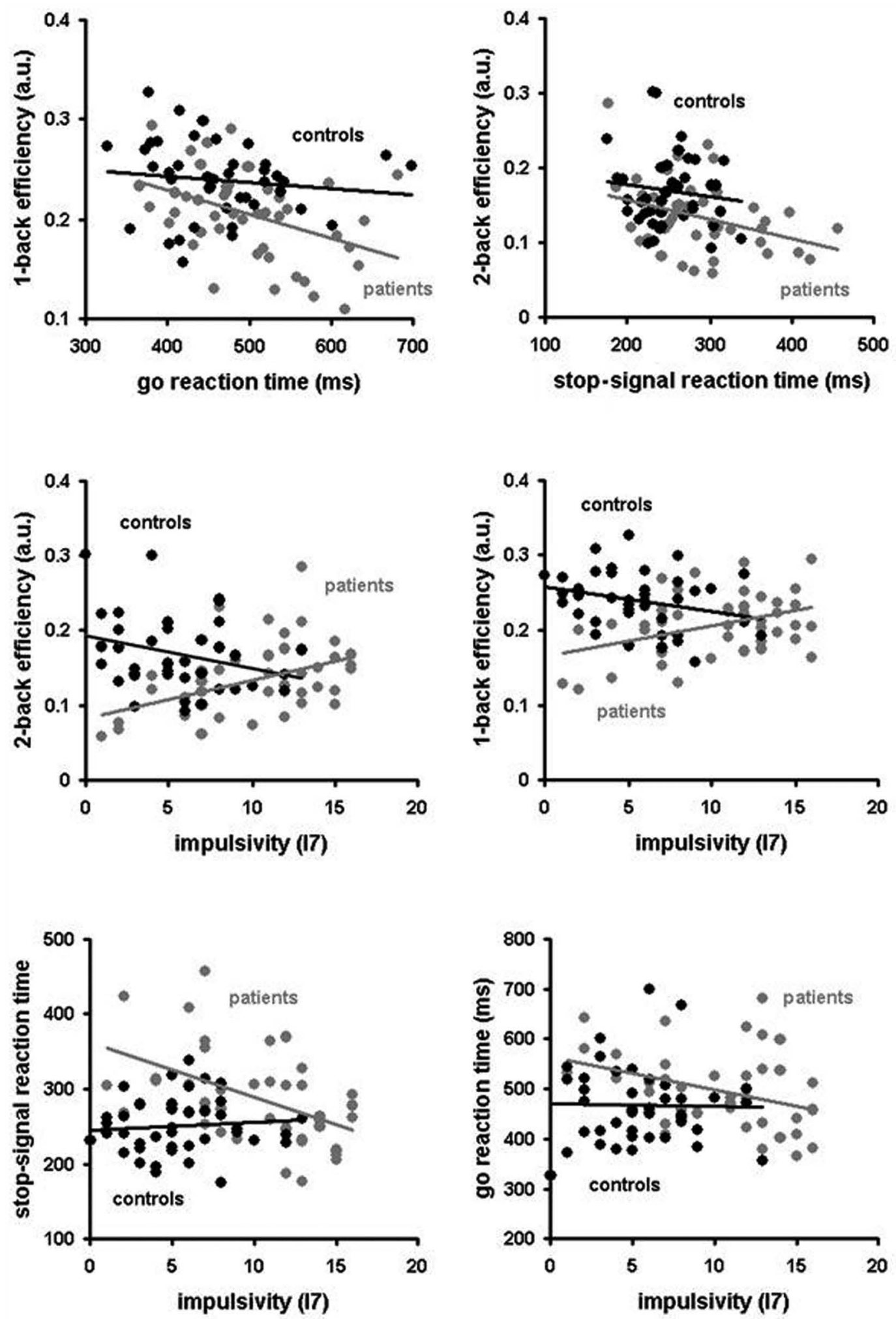

Figure 2. Scatterplots and regression lines according to significant correlations. Note: a.u. $=$ arbitrary units. 
$p<.001)$. For $\mathrm{HHb}$, solely, the condition effect was significant (condition: $F=6.6, p=.012$; group: $F=1.0, p=.319$; interaction: $F=0.6, p=.459$ ), indicating higher brain activation (lower $\mathrm{HHb}$ concentrations) during successful stop trials.

Correlational analyses of brain oxygenation revealed no significant associations with low effect sizes. Brain oxygenation during 1-back did not correlate with brain activation during go-trials neither for the patients $\left(\mathrm{O}_{2} \mathrm{Hb}: r=.089\right.$, $p=.563$; HHb: $r=-.036, p=.816$ ) nor for the controls $\left(\mathrm{O}_{2} \mathrm{Hb}: r=.273, p=.085\right.$; HHb: $\left.r=.001, p=.994\right)$. Brain oxygenation during 2-back did not correlate with brain oxygenation during successful stop trials neither for the patients $\left(\mathrm{O}_{2} \mathrm{Hb}: r=.020, p=.898\right.$; HHb: $\left.r=-.131, p=.392\right)$ nor the controls $\left(\mathrm{O}_{2} \mathrm{Hb}: r=.182, p=.255\right.$; HHb: $\left.r=.084, p=.601\right)$.

Correlation analyses with impulsivity, revealed no systematic significant correlations of brain oxygenation with I7 (patients: $-.219<r<.091$, all $p \mathrm{~s}>.164$; controls: $-.181<r$ $<.121$, all $p \mathrm{~s}>.259$ ) and DSM impulsivity measures (patients: $-.134<r<.128$, all $p \mathrm{~s}>.385$; controls: $-.251<r$ $<.235$, all $p \mathrm{~s}>.118$ ). For the group of patients, HHb during successful stop-signal trials was correlated with I7 impulsivity ( $r=-.261, p=.095)$, and for the group of controls, $\mathrm{O}_{2} \mathrm{Hb}$ during go was correlated with $D S M$ impulsivity $(r=$ $-.367, p=.020)$. These two unexpected correlations represented no systematic correlations and were interpreted as chance findings, that is, we abstained from deeper interpretation.

\section{Discussion}

We investigated 45 adult patients with ADHD and 41 comparable controls by means of an n-back and a stopsignal task and evaluated behavioral performance and amplitude changes in fNIRS signals indicating brain activation. Our analyses (ANOVAs) showed that the actual task conditions (2-back, stop signal) showed higher cognitive load and higher brain oxygenation (n-back: DLPFC; successful stops: IFC) as compared with the control conditions (1-back, go). These findings represent replications from the literature (Aron \& Poldrack, 2005; Owen, McMillan, Laird, \& Bullmore, 2005). In addition, patients showed diminished performance (1-back and 2-back efficiency, go RT and SSRT) and diminished brain oxygenation in the DLPFC for the 1-back and 2-back condition. Controls as compared with the patients had higher IFC $\mathrm{O}_{2} \mathrm{Hb}$ changes during successful stop trials in contrast to the control condition. Patients showed no stop task-associated brain oxygenation in the IFC. Several absent significant group differences for $\mathrm{HHb}$ - even if $\mathrm{HHb}$ showed the same activation pattern as $\mathrm{O}_{2} \mathrm{Hb}$ - might be due to the lower statistical power of $\mathrm{HHb}$ (S Schecklmann et al., 2008). In conclusion, we replicated numerous findings from the literature (see "Introduction" section), showing differences in performance and frontal brain activation between ADHD patients and healthy controls for WM and RI.
We also found control condition deficits in the group of patients. Behavioral deficits and alterations in brain functions have already been described for ADHD in simple psychomotor functions (Cole, Mostofsky, Larson, Denckla, \& Mahone, 2008; Miyazaki, Fujii, Saijo, Mori, \& Kagami, 2007; Mostofsky et al., 2006; Rommelse et al., 2008). In their review, Hervey et al. (2004) concluded that small differences between patients with ADHD and controls exist for simple motor and information processing tasks and that group differences increase with increasing cognitive load.

Beside the replication of group differences, our study was designed to test the hypothesis that RI and WM represent one phenotypic entity. Thus, the main interest of the present study was to correlate behavioral and functional WM and RI data to reveal information about a possible association of both processes. Strong associations between the different measures would indicate that WM and RI are actually part of one integrative phenotype. Only for the group of patients, we found a negative correlation with a medium effect size of 2-back efficiency and SSRT, on the behavioral level which indicates some association of both processes. This finding partially supports the hypothesis that WM and RI are part of one etiological pathway resulting in the clinical symptom of impulsivity (Barkley, 1997; Sonuga-Barke, 2002, 2005). However, the medium effect size and the fact that within the group of ADHD patients the control conditions (that is, 1-back efficiency and go-trial reaction time) intercorrelated with the same effect size, do not support this notion. This finding may be interpreted on the basis of the existing group differences in basal psychomotor processes or other condition-unspecific factors. Thus, correlation of WM and RI may rather be engendered by general factors such as attention or vigilance deficits or computer expertise.

For brain oxygenation, we did not find significant associations between the two tasks. This finding again does not support the hypothesis of an integrative executive phenotype of WM and RI in ADHD that is moderated via the prefrontal cortex.

We applied, for the first time, a correlation analysis approach that allowed for testing the integral nature of two phenotypic functions, rather than the mere fact that two functions involve the same brain regions. Significant correlations of oxygenation in different brain areas would raise the question as to which a third variable might mediate this association. Significant correlations (but not group differences) of oxygenation in the same brain areas would answer the question as to which brain areas constitute the core of one phenotype (compare introduction).

Our further analyses likewise render the integral executive phenotype concept implausible. High impulsivity scores in the I7 were associated with a better performance in measures of WM and RI in patients, whereas DSM impulsivity did not correlate with performance measures at all. 
Lijffijt et al. (2004) could not find support for a clear association of I7 impulsivity and SSRT when reviewing their own data and findings from four previous studies. However, it is unclear whether impulsivity in terms of behavioral task measures (SSRT; Chamberlain \& Sahakian, 2007; Winstanley et al., 2006) reflects the same construct as impulsivity on a phenotypic level as revealed by trait questionnaires, peer evaluation, or psychiatric examination. In line, we found no association of I7 impulsivity and DSM-IV impulsive symptoms. Consequently, this assumption also raises the question whether the (endo-)phenotype discussion is based on the correct measures. Thus, further studies have to carefully consider the underlying phenotype to be measured. In addition, the construct validity of the used measures has to be considered. As our data indicate, I7 trait impulsivity is probably more closely related to behavioral measures of impulsivity as elicited by the stop-signal task than to the number of impulsive symptoms of the phenotypic classification of ADHD as done by the DSM-IV. It should be noted that ADHD as classified by the DSM criteria is related to higher I7 scores and elongated SSRT; however, the correlation was only present between I7 and SSRT. Furthermore, the I7 scale is a dimensional questionnaire and the $D S M$ criteria are categorical measures becoming dimensional due to summation of these categorical criteria.

Interestingly, in his dual pathway model Sonuga-Barke (2005) described two causal circuits for ADHD, a cognitive and motivational developmental pathway. He referred executive deficits to inhibitory deficits (cognitive pathway) and associated motivational deficits to impulsivity (motivational pathway), indicating inhibition and impulsivity as the expression of two distinct functions. This model might be linked to the rather surprising correlations of I7 impulsivity and behavioral measures (especially SSRT). Considering the correlation analysis in the work at hand, it would be important for (endo-)phenotype research in ADHD to what extent the cognitive and motivational pathways are associated (Solanto et al., 2001).

In conclusion, these findings raise doubts regarding the validity of the observed association of WM and RI at the behavioral level in ADHD patients. As there is a large body of literature investigating ADHD patients with tasks of WM and RI by group comparison tests, we suggest the conduction of a meta-analysis that should result in mean correlation coefficients for certain task paradigms (e.g., go/no-go vs. stop task) with higher statistical power to further examine the hypothesis of WM and RI as one integrative phenotype. Another methodical approach might be the investigation of both processes in a two-factored design with the factor task (WM and RI) and the factor load (low and high WM or RI load). The interaction effect could reveal further information about a possible association of both processes. To our knowledge, some studies have so far investigated such interactions in healthy participants (Simmonds, Pekar, \&
Mostofsky, 2008). In contrast, in only one study, ADHD children and controls were investigated in a go/no-go task with low and high WM load (Wodka et al., 2007). The authors report group effects for go/no-go performance and a main effect of WM load, but no group by task interaction effect, which is in line with our findings and the literature.

One limitation of the present study is the high elimination rate that might be associated with a selection bias (patients with particularly severe symptomatology might have been systematically excluded). Reasons for elimination were high error rate insufficient task comprehension $(n=29)$, noisy signals $(n=8)$, and discontinuing of the measurement by the participants $(n=37)$. As a consequence, practice trials for the stop and WM task should be intensified, and measurements should not be elongated more than $30 \mathrm{~min}$ as this interval is perceived as too exhausting. Nonetheless, the final sample was a large clinical sample that was well diagnosed, and significant group differences would not have enough impact as we included better functioning patients. About half of the eliminated participants were excluded due to certain task design characteristics (e.g., long measurement time) or technical problems. Furthermore, the high rate of patients with personality disorders might have affected our findings. These sample characteristics might have limited the generalizability of the results to the whole ADHD population and might have influenced the group comparison and correlation results. This is in line with the finding that eliminated patients had although not significant-higher impulsivity scores. Another critical issue is that missing associations might be due to the present operationalizations of WM and RI (n-back and stop-signal task) or the operationalizations in separate tasks. Nevertheless, we used common task paradigms for WM and RI, and other operationalizations (compare introduction) also do not account for a clear association of these functions. We also found significant group differences and correlations for the control conditions. Control conditions possibly included components of WM or RI. In the WM task, the 1-back condition also requires a WM component, even if the WM load is very low. Furthermore, for the stop task, participants had to press one button and inhibit the press of another. Thus, the basal go-trials might contain an inhibitory component. Thus, we might not have implemented appropriate or "real" control conditions. Nonetheless, 2-back or stop trials should invoke even more WM or RI processes than 1-back or go-trials. A further critical note is the use of fNIRS allowing only the measurement of restricted brain areas. Thus, future studies with comparable questions should use additional imaging methods (e.g., fMRI) allowing for the assessment of the whole brain.

In conclusion, previous studies and the present findings could not reveal clear associations of WM and RI in ADHD patients, which raises doubts regarding the suggestion that both processes are part of one integrative phenotype 
mediated by the prefrontal cortex oxygenation (Barkley, 1997; Sonuga-Barke, 2002, 2005).

\section{Acknowledgements}

The authors would like to thank Hitachi Medical Corporation for the ETG-4000 equipment and Ramona Taeglich for her proficient technical assistance. This manuscript is part of the dissertation of Martin Schecklmann.

\section{Declaration of Conflicting Interests}

The author(s) declared no potential conflicts of interest with respect to the research, authorship, and/or publication of this article.

\section{Funding}

The author(s) disclosed receipt of the following financial support for the research, authorship, and/or publication of this article: The study was supported by the Deutsche Forschungsgemeinschaft, KFO 125-1 and SFB TRR 59 (C4).

\section{References}

Alderson, R. M., Rapport, M. D., Hudec, K. L., Sarver, D. E., \& Kofler, M. J. (2010). Competing core processes in attentiondeficit/hyperactivity disorder (ADHD): Do working memory deficiencies underlie behavioral inhibition deficits? Journal of Abnormal Child Psychology, 38, 497-507.

American Psychiatric Association. (1994). Diagnostic and statistical manual of mental disorders (4th ed.). Washington, DC: Author.

Aron, A. R., \& Poldrack, R. A. (2005). The cognitive neuroscience of response inhibition: Relevance for genetic research in attention-deficit/hyperactivity disorder. Biological Psychiatry, 57, 1285-1292.

Band, G. P., van der Molen, M. W., \& Logan, G. D. (2003). Horserace model simulations of the stop-signal procedure. Acta Psychologica, 112, 105-142.

Barkley, R. A. (1997). Behavioral inhibition, sustained attention, and executive functions: Constructing a unifying theory of ADHD. Psychological Bulletin, 121, 65-94.

Boonstra, A. M., Oosterlaan, J., Sergeant, J. A., \& Buitelaar, J. K. (2005). Executive functioning in adult ADHD: A metaanalytic review. Psychological Medicine, 35, 1097-1108.

Castellanos, F. X., \& Tannock, R. (2002). Neuroscience of attentiondeficit/hyperactivity disorder: The search for endophenotypes. Nature Reviews Neuroscience, 3, 617-628.

Chamberlain, S. R., \& Sahakian, B. J. (2007). The neuropsychiatry of impulsivity. Current Opinion in Psychiatry, 20, 255-261.

Clark, L., Blackwell, A. D., Aron, A. R., Turner, D. C., Dowson, J., Robbins, T. W., \& Sahakian, B. J. (2007). Association between response inhibition and working memory in adult ADHD: A link to right frontal cortex pathology? Biological Psychiatry, 61, 1395-1401.

Cohen, J. (1988). Statistical power analysis for the behavioral sciences. Hillsdale, NJ: Lawrence Erlbaum.
Cole, W. R., Mostofsky, S. H., Larson, J. C., Denckla, M. B., \& Mahone, E. M. (2008). Age-related changes in motor subtle signs among girls and boys with ADHD. Neurology, 71, 1514-1520.

Dickstein, S. G., Bannon, K., Castellanos, F. X., \& Milham, M. P. (2006). The neural correlates of attention deficit hyperactivity disorder: An ALE meta-analysis. Journal of Child Psychology and Psychiatry, 47, 1051-1062.

Durston, S. (2003). A review of the biological bases of ADHD: What have we learned from imaging studies? Mental Retardation and Developmental Disabilities Research Reviews, 9, 184-195.

Eysenck, S. B., \& Eysenck, H. J. (1977). The place of impulsiveness in a dimensional system of personality description. British Journal of Social and Clinical Psychology, 16, 57-68.

Eysenck, S. B. G., Daum, I., Schugens, M. M., \& Diehl, J. M. (1990). A cross-cultural study of impulsiveness, venturesomeness and empathy: Germany and England. Zeitschrift für Differentielle und Diagnostische Psychologie, 11, 209-213.

Eysenck, S. B. G., \& Eysenck, H. J. (1980). Impulsiveness and venturesomeness in children. Personality and Individual Differences, 1, 73-78.

Fallgatter, A. J., Ehlis, A., Wagener, A., Michel, T., \& Herrmann, M. J. (2004). Nah-Infrarot-Spektroskopie in der Psychiatrie [Nearinfrared spectroscopy in psychiatry]. Nervenarzt, 75, 911-916.

Friston, K. J., Holmes, A. P., Poline, J. B., Grasby, P. J., Williams, S. C., Frackowiak, R. S., \& Turner, R. (1995). Analysis of fMRI time-series revisited. Neuroimage, 2, 45-53.

Geurts, H. M., Verte, S., Oosterlaan, J., Roeyers, H., \& Sergeant, J. A. (2005). ADHD subtypes: Do they differ in their executive functioning profile? Archives of Clinical Neuropsychology, 20, 457-477.

Gottesman, I. I., \& Gould, T. D. (2003). The endophenotype concept in psychiatry: Etymology and strategic intentions. American Journal of Psychiatry, 160, 636-645.

Heeger, D. J., \& Ress, D. (2002). What does fMRI tell us about neuronal activity? Nature Reviews Neuroscience, 3, 142-151.

Hervey, A. S., Epstein, J. N., \& Curry, J. F. (2004). Neuropsychology of adults with attention-deficit/hyperactivity disorder: A meta-analytic review. Neuropsychology, 18, 485-503.

Hoshi, Y. (2007). Functional near-infrared spectroscopy: Current status and future prospects. Journal of Biomedical Optics, $12(6), 062106$.

Huppert, T. J., Hoge, R. D., Diamond, S. G., Franceschini, M. A., \& Boas, D. A. (2006). A temporal comparison of BOLD, ASL, and NIRS hemodynamic responses to motor stimuli in adult humans. Neuroimage, 29, 368-382.

Jacob, C., \& Lesch, K. P. (2006). The Wuerzburg research initiative on adult attention-deficit/hyperactivity disorder (WURINAADHD): Multi-layered evaluation of long-term course. European Archives of Psychiatry and Clinical Neuroscience, 256(Suppl. 1), i12-20.

Jaeggi, S. M., Buschkuehl, M., Perrig, W. J., \& Meier, B. (2010). The concurrent validity of the n-back task as a working memory measure. Memory, 18, 394-412. 
Jasper, H. H. (1958). The ten-twenty electrode system of the International Federation. Electroencephalography and Clinical Neurophysiology, 10, 371-375.

Kirk, J. W., Mazzocco, M. M., \& Kover, S. T. (2005). Assessing executive dysfunction in girls with fragile $\mathrm{X}$ or Turner syndrome using the Contingency Naming Test (CNT). Developmental Neuropsychology, 28, 755-777.

Lehrl, S. (2005). Mehrfachwahl-Wortschatz-Intelligenztest MWT$B$. Balingen, Germany: Spitta Verlag.

Lijffijt, M., Bekker, E. M., Quik, E. H., Bakker, J., Kenemans, J. L., \& Verbaten, M. N. (2004). Differences between low and high trait impulsivity are not associated with differences in inhibitory motor control. Journal of Attention Disorders, 8, 25-32.

Lijffijt, M., Kenemans, J. L., Verbaten, M. N., \& van Engeland, H. (2005). A meta-analytic review of stopping performance in attention-deficit/hyperactivity disorder: Deficient inhibitory motor control? Journal of Abnormal Psychology, 114, 216-222.

Logan, G. D. (1994). On the ability to inhibit thought and action: A users' guide to the stop signal paradigm. In D. Dagenbach \& T. H. Carr (Eds.), Inhibitory processes in attention, memory, and language (pp. 189-239). San Diego, CA: Academic Press.

Logan, G. D., Schachar, R. J., \& Tannock, R. (1997). Impulsivity and inhibitory control. Psychological Science, 8, 60-64.

Logothetis, N. K., \& Wandell, B. A. (2004). Interpreting the BOLD signal. Annual Review in Physiology, 66, 735-769.

Mahone, E. M., Pillion, J. P., Hoffman, J., Hiemenz, J. R., \& Denckla, M. B. (2005). Construct validity of the auditory continuous performance test for preschoolers. Developmental Neuropsychology, 27(1), 11-33.

Martinussen, R., Hayden, J., Hogg Johnson, S., \& Tannock, R. (2005). A meta-analysis of working memory impairments in children with attention-deficit/hyperactivity disorder. Journal of the American Academy of Child \& Adolescent Psychiatry, 44, 377-384.

McNab, F., Leroux, G., Strand, F., Thorell, L., Bergman, S., \& Klingberg, T. (2008). Common and unique components of inhibition and working memory: An fMRI, within-subjects investigation. Neuropsychologia, 46, 2668-2682.

Miyazaki, M., Fujii, E., Saijo, T., Mori, K., \& Kagami, S. (2007). Somatosensory evoked potentials in attention deficit/ hyperactivity disorder and tic disorder. Clinical Neurophysiology, 118, 1286-1290.

Mostofsky, S. H., Rimrodt, S. L., Schafer, J. G., Boyce, A., Goldberg, M. C., Pekar, J. J., \& Denckla, M. B. (2006). Atypical motor and sensory cortex activation in attentiondeficit/hyperactivity disorder: A functional magnetic resonance imaging study of simple sequential finger tapping. Biological Psychiatry, 59, 48-56.

Mullane, J. C., \& Corkum, P. V. (2007). The relationship between working memory, inhibition, and performance on the Wisconsin Card Sorting Test in children with and without ADHD. Journal of Psychoeducational Assessment, 25, 211-221.
Obrig, H., \& Villringer, A. (2003). Beyond the visible-Imaging the human brain with light. Journal of Cerebral Blood Flow \& Metabolism, 23, 1-18.

Okamoto, M., Dan, H., Sakamoto, K., Takeo, K., Shimizu, K., Kohno, S., . . . Dan, I. (2004). Three-dimensional probabilistic anatomical cranio-cerebral correlation via the international 10-20 system oriented for transcranial functional brain mapping. Neuroimage, 21, 99-111.

Owen, A. M., McMillan, K. M., Laird, A. R., \& Bullmore, E. (2005). N-back working memory paradigm: A meta-analysis of normative functional neuroimaging studies. Human Brain Mapping, 25, 46-59.

Pasini, A., Paloscia, C., Alessandrelli, R., Porfirio, M. C., \& Curatolo, P. (2007). Attention and executive functions profile in drug naive ADHD subtypes. Brain \& Development, 29, 400-408.

Plichta, M. M., Heinzel, S., Ehlis, A. C., Pauli, P., \& Fallgatter, A. J. (2007). Model-based analysis of rapid event-related functional near-infrared spectroscopy (NIRS) data: A parametric validation study. Neuroimage, 35, 625-634.

Plichta, M. M., Herrmann, M. J., Baehne, C. G., Ehlis, A. C., Richter, M. M., Pauli, P., \& Fallgatter, A. J. (2007). Eventrelated functional near-infrared spectroscopy (fNIRS) based on craniocerebral correlations: Reproducibility of activation? Human Brain Mapping, 28, 733-741.

Pliszka, S. R. (2007). Pharmacologic treatment of attention-deficit/ hyperactivity disorder: Efficacy, safety and mechanisms of action. Neuropsychology Review, 17, 61-72.

Retz-Junginger, P., Retz, W., Blocher, D., Stieglitz, R. D., Georg, T., Supprian, T., . . . Rösler, M. (2003). Reliabilitat und Validitat der Wender-Utah-Rating-Scale-Kurzform. Retrospektive Erfassung von Symptomen aus dem Spektrum der Aufmerksamkeitsdefizit/Hyperaktivitatsstorung. [Reliability and validity of the Wender-Utah-Rating-Scale-Short Form. Retrospective assessment of symptoms for attention deficit/ hyperactivity disorder]. Nervenarzt, 74, 987-993.

Rommelse, N. N., Van der Stigchel, S., Witlox, J., Geldof, C., Deijen, J. B., Theeuwes, J., . . Sergeant, J. A. (2008). Deficits in visuo-spatial working memory, inhibition and oculomotor control in boys with ADHD and their non-affected brothers. Journal of Neural Transmission, 115, 249-260.

Rovati, L., Salvatori, G., Bulf, L., \& Fonda, S. (2007). Optical and electrical recording of neural activity evoked by graded contrast visual stimulus. Biomedical Engineering Online, 6, 28.

Sass, H., Wittchen, H. U., \& Zaudig, M. (1996). DSM-IV Diagnostisches und Statistisches Manual Psychischer Stoerungen IV [Diagnostic and statistical manual of mental disorders]German version. Göttingen, Germany: Hogrefe.

Schecklmann, M., Ehlis, A. C., Plichta, M. M., \& Fallgatter, A. J. (2008). Functional near-infrared spectroscopy: A long-term reliable tool for measuring brain activity during verbal fluency. Neuroimage, 43, 147-155. 
Schecklmann, M., Romanos, M., Bretscher, F., Plichta, M. M., Warnke, A., \& Fallgatter, A. J. (2010). Prefrontal oxygenation during working memory in ADHD. Journal of Psychiatric Research, 44, 621-628.

Schneider, M., Retz, W., Coogan, A., Thome, J., \& Rosler, M. (2006). Anatomical and functional brain imaging in adult attention-deficit/hyperactivity disorder (ADHD) — A neurological view. European Archives of Psychiatry and Clinical Neuroscience, 256(Suppl. 1), i32-i41.

Schoechlin, C., \& Engel, R. R. (2005). Neuropsychological performance in adult attention-deficit hyperactivity disorder: Meta-analysis of empirical data. Archives of Clinical Neuropsychology, 20, 727-744.

Simmonds, D. J., Pekar, J. J., \& Mostofsky, S. H. (2008). Metaanalysis of go/no-go tasks demonstrating that fMRI activation associated with response inhibition is task-dependent. Neuropsychologia, 46, 224-232.

Solanto, M. V., Abikoff, H., Sonuga Barke, E., Schachar, R., Logan, G. D., Wigal, T., . . Turkel, E. (2001). The ecological validity of delay aversion and response inhibition as measures of impulsivity in AD/HD: A supplement to the NIMH multimodal treatment study of AD/HD. Journal of Abnormal Child Psychology, 29, 215-228.

Sonuga-Barke, E. J. (2002). Psychological heterogeneity in $\mathrm{AD} / \mathrm{HD}$ - A dual pathway model of behaviour and cognition. Behavioral Brain Research, 130, 29-36.

Sonuga-Barke, E. J. (2005). Causal models of attention-deficit/ hyperactivity disorder: From common simple deficits to multiple developmental pathways. Biological Psychiatry, 57, 1231-1238.

Sonuga-Barke, E. J., Dalen, L., Daley, D., \& Remington, B. (2002). Are planning, working memory, and inhibition associated with individual differences in preschool ADHD symptoms? Developmental Neuropsychology, 21, 255-272.

Soreni, N., Crosbie, J., Ickowicz, A., \& Schachar, R. (2009). Stop signal and Conners' continuous performance tasks: Testretest reliability of two inhibition measures in ADHD children. Journal of Attention Disorders, 13, 137-143.

Tegeler, C., Strother, S. C., Anderson, J. R., \& Kim, S. G. (1999). Reproducibility of BOLD-based functional MRI obtained at 4 T. Human Brain Mapping, 7, 267-283.

Tsujimoto, S., Kuwajima, M., \& Sawaguchi, T. (2007). Developmental fractionation of working memory and response inhibition during childhood. Experimental Psychology, 54, 30-37.

Verte, S., Geurts, H. M., Roeyers, H., Oosterlaan, J., \& Sergeant, J. A. (2006). The relationship of working memory, inhibition, and response variability in child psychopathology. Journal of Neuroscience Methods, 151, 5-14.

Willcutt, E. G., Doyle, A. E., Nigg, J. T., Faraone, S. V., \& Pennington, B. F. (2005). Validity of the executive function theory of attention-deficit/hyperactivity disorder: A metaanalytic review. Biological Psychiatry, 57, 1336-1346.

Winstanley, C. A., Eagle, D. M., \& Robbins, T. W. (2006). Behavioral models of impulsivity in relation to ADHD: Translation between clinical and preclinical studies. Clinical Psychology Review, 26, 379-395.

Wittchen, H. U., Zaudig, M., \& Fydrich, T. (1997). SKID-I/II Strukturiertes Klinisches Interview fuer $D S M-I V$ [Users Guide for the Structured Clinical Interview for DSM-IV] - German modified version. Göttingen, Germany: Hogrefe.

Wodka, E. L., Mahone, E. M., Blankner, J. G., Larson, J. C., Fotedar, S., Denckla, M. B., \& Mostofsky, S. H. (2007). Evidence that response inhibition is a primary deficit in ADHD. Journal of Clinical and Experimental Neuropsychology, 29, 345-356.

Woods, S. P., Lovejoy, D. W., \& Ball, J. D. (2002). Neuropsychological characteristics of adults with ADHD: A comprehensive review of initial studies. Clinical Neuropsychologist, $16,12-34$

Zobel, A., \& Maier, W. (2004). Endophanotypen-ein neues Konzept zur biologischen Charakterisierung psychischer Storungen. [Endophenotype-A new concept for biological characterization of psychiatric disorders]. Nervenarzt, 75, 205-214.

\section{Author Biographies}

Martin Schecklmann, psychologist, $\mathrm{PhD}$, is a research associate at the University of Regensburg, Department of Psychiatry, Germany.

Ann-Christine Ehlis, psychologist, $\mathrm{PhD}$, is a research associate at the University of Tübingen, Department of Psychiatry, Germany.

Michael M. Plichta, psychologist, $\mathrm{PhD}$, is a research associate at the University of Heidelberg, Central Institute of Mental Health, Germany.

Thomas Dresler, psychologist, $\mathrm{PhD}$, is a research associate at the University of Würzburg, Department of Psychiatry, Germany.

Monika Heine, MD, is a resident at the University of Würzburg, Department of Psychiatry, Germany.

Andrea Boreatti-Hümmer, MD, is a resident at the University of Würzburg, Department of Psychiatry, Germany.

Marcel Romanos, MD, is a senior physician at the University of Munich, Department of Child and Adolescent Psychiatry, Germany.

Christian Jacob, MD, is a senior physician at the University of Würzburg, Department of Psychiatry, Germany.

Paul Pauli, psychologist, $\mathrm{PhD}$, is professor at the University of Würzburg, Department of Psychology, Germany.

Andreas J. Fallgatter, MD, is head of a department at the University of Tübingen, Department of Psychiatry, Germany 